\title{
A estética do cine-olho nas imagens em protestos ${ }^{1}$
}

\section{The aesthetics of kino-eye in images from the flow of protests}

\author{
Alexandre Rocha da Silva \\ Professor pós-doutor e vice-coordenador do Programa de Pós-Graduação em Comunicação e Informação da Faculdade de \\ Biblioteconomia e Comunicação da Universidade Federal do Rio Grande do Sul (UFRGS), editor da Revista Intexto, coordenador \\ do Grupo de Pesquisa Semiótica da Comunicação da Sociedade Brasileira de Estudos Interdisciplinares da Comunicação \\ (Intercom) e coordenador do Diretório CNPq Semiótica e culturas da comunicação (GPESC). \\ <arsrocha@gmail.com>
}

\section{Bruno Bueno Pinto Leites}

Doutorando em Comunicação e Informação na Universidade Federal do Rio Grande do Sul (UFRGS) e Mestre em Ciências da Comunicação pela Universidade do Vale do Rio dos Sinos (UNISINOS), é professor substituto nos cursos de Cinema da Universidade Federal de Pelotas (UFPel).

<bleites2003@hotmail.com>

\section{RESUMO}

Este trabalho introduz uma proposta para análise de imagens feitas em fluxos de protestos. Para tanto, (1) retoma o conceito de estética proposto por Jacques Rancière; (2) revisita as teses de Dziga Vertov sobre o cine-olho, para seguir um antigo sonho das imagens - confundir-se com a matéria dos acontecimentos; (3) analisa imagens produzidas nos protestos de 2013 no Brasil, destacando, entre outros elementos, as deformações. Deste modo, é possível indicar uma rede de agenciamentos estético-políticos que essas imagens vêm fomentar, rede esta que implica um apagamento da distinção entre acontecimento e imagem e que ecoa os modos contemporâneos de organização coletiva que se pretendem a-centrados.

\begin{abstract}
This article introduces a proposal for studying images made in the flow of protests. In order to do so, (1) it is examined the concept of aesthetics in Jacques Rancière; (2) it is revisited the thesis of Dziga Vertov on the kino-eye to follow a long-lasting dream of images - being immerse in the substance of events; and (3) it is analyzed images from the 2013 protests in Brazil with emphasis on the process of losing forms and definition, among other aspects. Thus, it is possible to consider political and aesthetical assemblages in which those images take part, often associated with fading the rigid separation between event and image and with the emergence of contemporary decentered methods of collective organization.
\end{abstract}

Keywords: Image. Vertov. Protests.

\section{Introdução}

Nos protestos populares havidos nos últimos anos na Europa, na África, na América do Norte e no Brasil, as câmeras passaram a ter um enigmático protagonismo. A existência das câmeras no olho dos protestos instaura novas

1 Pesquisa financiada pelo CNPq e pela CAPES. 
visibilidades e, por isso, tem o potencial de produzir instabilidades. É comum assistir cenas em que o uso da câmera é questionado, tanto pelas forças policiais, quando se trata de registro amador, quanto pelos populares, quando se trata de registro feito pelas grandes empresas de comunicação.

A imagem abaixo mostra o portador da câmera durante abordagem da polícia. Ele tenta manter ligado o dispositivo o máximo que pode, mesmo que na maior parte do tempo não consiga estabilizar a imagem nem direcionar o enquadramento (Figura1). Quando a polícia coloca o portador no camburão, a primeira atitude é fazer desligar o dispositivo de gravação de imagem, como vemos em outro vídeo do mesmo evento (PRISÃO do repórter..., sem autoria, 2013).

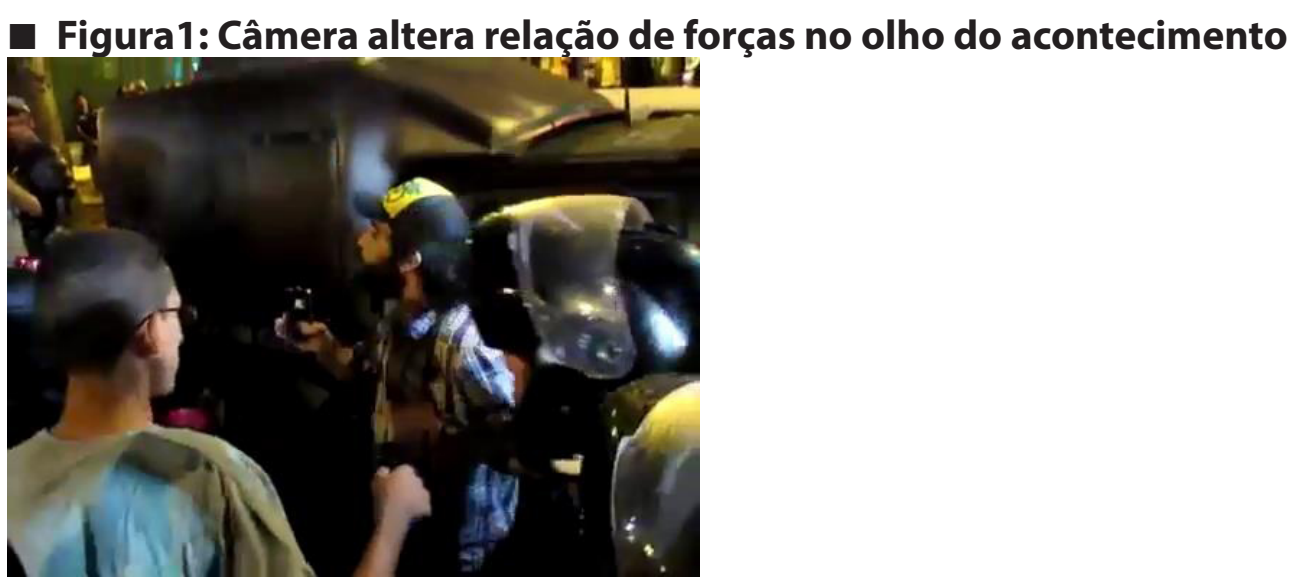

Fonte: Prisão do Carioca..., sem autoria, 2013

Agressões diretas à câmera ocorrem sobretudo com mãos, cassetetes e sprays de pimenta. Na imagem abaixo (Figura 2), vemos o gesto de dirigir-se à câmera para torná-la inoperante. O portador da câmera havia se aproximado demais do foco da ação e estava tentando interferir diretamente com a câmera e com palavras. $O$ primeiro gesto do policial é mover a mão contra a lente. Como o portador da câmera também usa a mão para proteger o aparelho, vemos uma disputa corporal direta e imediata pela garantia da possibilidade de imagem. Em outra, destaca-se o esforço do manifestante para salvar a própria câmera, mesmo que isso implique deixar desprotegido seu corpo (Figura 3). Nesse mesmo vídeo, vemos que também o foco da abordagem dos policiais é mais a câmera do que o próprio manifestante. 
- Figuras 2 e 3: Tentativas de silenciar e proteger o equipamento

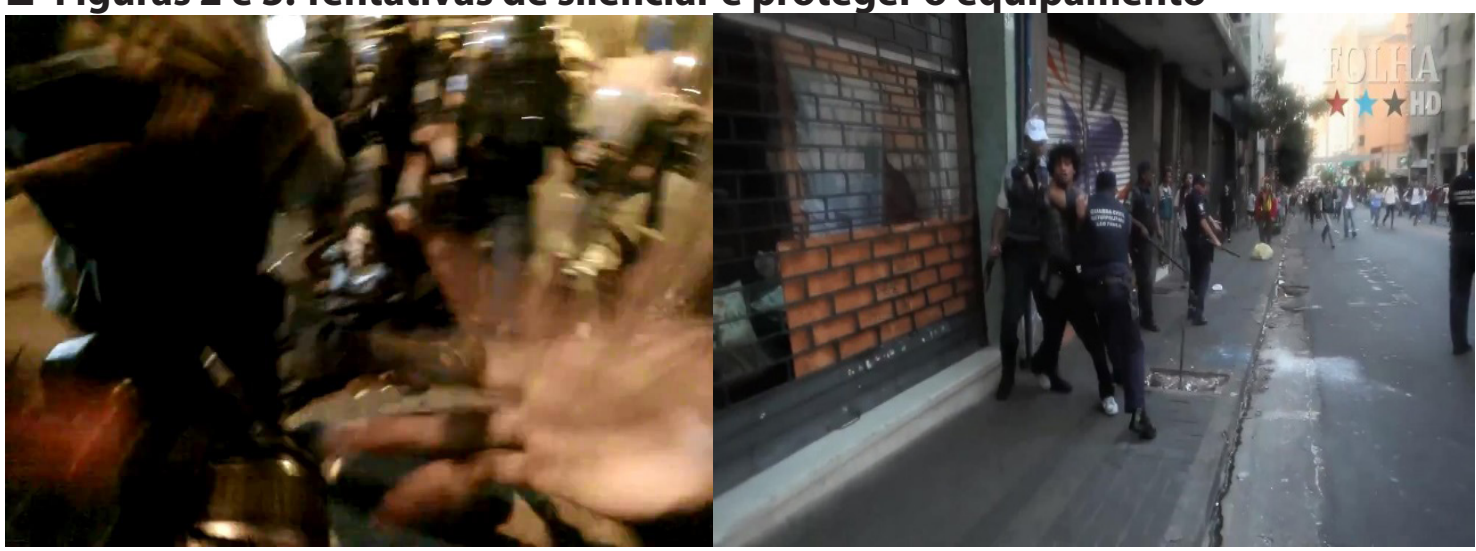

Fontes: Lapa 5aDp..., sem autoria, 2013 e Repórter da...., TV Folha, 2011.

Após serem capturadas, as imagens dessas câmeras circulam de modo errático, sobretudo na internet e na televisão; mas também servem de material bruto para documentários cinematográficos. É o caso de filmes feitos com imagens provenientes dos protestos da "Batalha de Seattle", ocorrida em novembro de 1999, por ocasião de um encontro da Organização Mundial do Comércio na cidade de Seattle, nos Estados Unidos. Dentre os filmes, destacamse: Breaking the spell (Tim Lewis, Tim Ream e Sir Chuck A. Rock, 1999); This is what democracy looks like (Jill Friedberg e Rick Rowley, 1999); 30 frames a second: The WTO in Seatle 2000 (Rustin Thompson, 2000). No Brasil, citamos os filmes Com vandalismo (Coletivo Nigéria, 2013) e A partir de agora (Carlos Pronzato, 2014). ${ }^{2}$ As imagens provenientes de uma massa em fluxo e muitas vezes sem autoria individual são narrativizadas quando chegam aos noticiários de televisão, aos sites de compartilhamentos de vídeos na internet e às redes sociais. É neste âmbito que ocorre uma batalha política de apropriação, uma espécie de montagem do material bruto produzido muitas vezes por fontes anônimas.

Salientamos que as imagens produzidas pelas câmeras em protestos vêm ocupar o cenário audiovisual e produzir transformações estéticas e políticas no universo de imagens contemporâneas. Para compreender o universo dessas imagens, apostamos na perspectiva estética de Jacques Rancière (2005). A

2 This is what democracy looks like, segundo letreiro que antecede o filme, foi realizado com material bruto de mais de 100 videografistas que participaram dos protestos. Breaking the spell utiliza imagens amadoras de fontes diversas advindas dos protestos. 30 frames a second é resultado do trabalho de Rustin Thompson como jornalista freelancer inserido nos protestos. Com vandalismo foi realizado de modo colaborativo por integrantes do Coletivo Nigéria. A partir de agora é realizado por meio de entrevistas que tentam atribuir sentido aos protestos, neste caso, as imagens dos protestos constam como ilustração. 
estética em Rancière é o terreno das potencialidades, daquilo que está em via de se tornar visível. Quando se torna visível, toma parte nos jogos da política. Logo, para além de compreender as imagens das câmeras em fluxos de protestos sob o ponto de vista político, destacamos a necessidade de compreendê-las do ponto de vista estético, porque elas agem produzindo novas linhas de visibilidade. Isso fica evidente no protagonismo e na perseguição às câmeras durante protestos. Elas, as câmeras, desenham um novo terreno de visibilidade, que, por um lado, fascina, e, por outro, ameaça. A potência dessas imagens é resultado de uma complexa intersecção, em que incidem critérios tecnológicos, como a portabilidade das câmeras, e na qual se atualiza um antigo projeto do cinema: constituir um cine-olho, como no projeto de Dziga Vertov, imerso no fluxo dos acontecimentos, confundido com a matéria da vida.

\section{Das relações entre Estética e Política}

Jacques Rancière (2005) considera que a partilha do sensível compreende uma peculiar relação de compartilhamento e de diferença nos âmbitos da estética e da política. Ambas atuam nas disputas acerca do comum, do que neste comum se partilha e do que neste comum se diferencia. Desde esta perspectiva, é equivocada a compreensão de que em determinado momento a política apropriou-se da estética. Trata-se de uma postulação recorrente para qualificar espaços políticos cujas ações estão orquestradas para efeitos midiáticos. Rancière faz sua crítica especificamente a Walter Benjamin, que vê a estetização da política como uma consequência nefasta de uma era específica, a era do fascismo (Rancière, 2005). Segundo Benjamin, o cinema e a fotografia permitiam mostrar a massa às massas, numa espécie de jogo político em que as massas supostamente teriam voz, mas sem a possuir de fato, já que as relações de poder e a propriedade dos meios de produção não haviam mudado. É este o sistema construído pelo fascismo, ao se apropriar da potência da obra de arte tecnicamente reprodutível. Em suma, para Benjamin, a estetização é um procedimento que instaura um ambiente estético-político próprio ao sistema de massas, que a um só tempo ilude as massas com uma suposta participação política (e assim inibe a revolução), e retira a potência própria da política (Benjamin, 1987).

Em Rancière, a relação entre estética e política é atemporal, no sentido de que não existe apenas em determinados períodos. A estética designa o que deve ser visto e o que não deve ser visto, as relações entre o visível e o dizível, os 
recortes de tempo e espaço. Ela determina, assim, inclusive o que deve entrar no jogo da política (Rancière, 2005).

De certo que essa noção de estética, ainda que formalmente precisa, parece demasiadamente ampliada. Nessa perspectiva, tudo o que se faz em termos de organização e rupturas entre as lógicas de visibilidade e invisibilidade são da ordem da estética? Não haveria outros âmbitos de atividades que provocariam rupturas nesse universo? Ainda que brevemente, Rancière aborda a problemática:

É a partir dessa estética primeira que se pode colocar a questão das "práticas estéticas", no sentido em que entendemos, isto é, como formas de visibilidade das práticas de arte, do lugar que ocupam, do que "fazem" no que diz respeito ao comum. As práticas artísticas são "maneiras de fazer" que intervêm na distribuição geral das maneiras de fazer e nas suas relações com maneiras de ser e formas de visibilidade (Rancière, 2005, p. 17).

Como visto, Rancière atribui ao conceito de estética uma generalidade a que chama de "estética primeira". Em seguida, delimita o universo das "práticas artísticas" e é explícito ao afirmar que tais práticas intervêm no âmbito mais geral das maneiras de fazer e nas suas relações com as maneiras de ser e as formas de visibilidade. É a relação entre estética primeira e política que vai compor a partilha do sensível. Partilha é um termo que designa em um mesmo processo um movimento de tornar comum e de separar partes exclusivas.

Para Rancière, o cinema e a fotografia não instauraram a modernidade e tampouco um novo regime de arte. Pelo contrário, eles encontraram o fértil leito para desenvolverem-se na esteira do regime estético das artes. Em primeiro lugar, o autor critica Benjamin e as explicações que pautam as transformações da arte em termos de evolução técnica. Em seguida, ele inverte o argumento: foi apenas devido ao regime estético que o cinema e a fotografia puderam constituir-se como arte, e não permanecer como aparato unicamente de reprodução e difusão. O cinema e a fotografia tornaram-se arte tematizando o comum, o anônimo, o cotidiano sem importância para as regras do sistema clássico representativo. Rancière reconhece a potência do cinema e da fotografia no que tange à tematização das massas, conforme dita por Benjamin, mas afirma que isso não começou com a reprodutibilidade técnica, mas sim com o realismo romanesco, quando pôs em igualdade todos os temas e todas as formas de expressão artísticas (Rancière, 2005). 
Logo, quando estabelecemos a relação entre Estética e Política com base em Rancière, torna-se pertinente reconhecer que: a) a estética tem sempre uma implicação política, porque determina aquilo que pode ou não pode tornar-se visível e dizível; b) a estética é composta por um grande número de agentes que participam dos jogos de poder na sociedade. A arte, as práticas artísticas, são uma prática entre várias, e necessitam disputar espaço com toda a sorte de produção midiática e comercial. Concluímos ainda que as consolidações estéticas de cada época não são imunes a uma disputa de força e que, portanto, novas estéticas implicam desconfortos e tendem a suscitar reações.

\section{O cine-olho e a imagem como movimento de mundo}

O cineasta soviético Dziga Vertov produziu seu trabalho mais relevante entre o final dos anos 1910 e, principalmente, durante os anos 1920. Ele viveu em uma época em que o cinema ainda estava se consolidando como arte e como indústria do entretenimento, e pode ser considerado um dos primeiros grandes teóricos da imagem em movimento. Vertov estava, também, inserido em um contexto de crença nas máquinas, na eletricidade, no automóvel, na industrialização da União Soviética, em uma cultura que produziu o Futurismo, movimento artístico influenciado pelo grande desenvolvimento tecnológico do final do século XIX e início do século XX.

\footnotetext{
O olho mecânico, a câmera, que se recusa a utilizar o olho humano como lembrete, tateia no caos dos acontecimentos visuais, deixandose atrair ou repelir pelos movimentos, buscando o caminho de seu próprio movimento ou de sua própria oscilação; e faz experiência de estiramento do tempo, de fragmentação do movimento ou, ao contrário, de absorção do tempo em si mesmo, da deglutição dos anos, esquematizando, assim, processos de longa duração inacessíveis ao olho normal... (Vertov, 1983a, p. 257).
}

Vertov procurou extrair o máximo desta concepção, levando a câmera ao ponto de uma percepção puramente maquínica (Deleuze, 1983). Deste ponto de vista, a comparação do olho humano com o olho da máquina soa injusta: o olho humano será sempre imperfeito, falível, composto por clichês. O cine-olho, por outro lado, será total, preciso e infalível. 
A imagem abaixo (Figura 4), de O homem com a câmera (Dziga Vertov, 1929), é explícita deste projeto. Através da sobreposição, o cineasta faz a câmera ser uma parte da matéria. Ela não filma o objeto, ela se insere dentro do objeto. Por isso, vemos à esquerda do quadro a câmera e o operador, mas eles terminam por se tornar indissociáveis da própria matéria quando se aproximam do centro do quadro.

- Figura 4: Câmera se confunde com a matéria

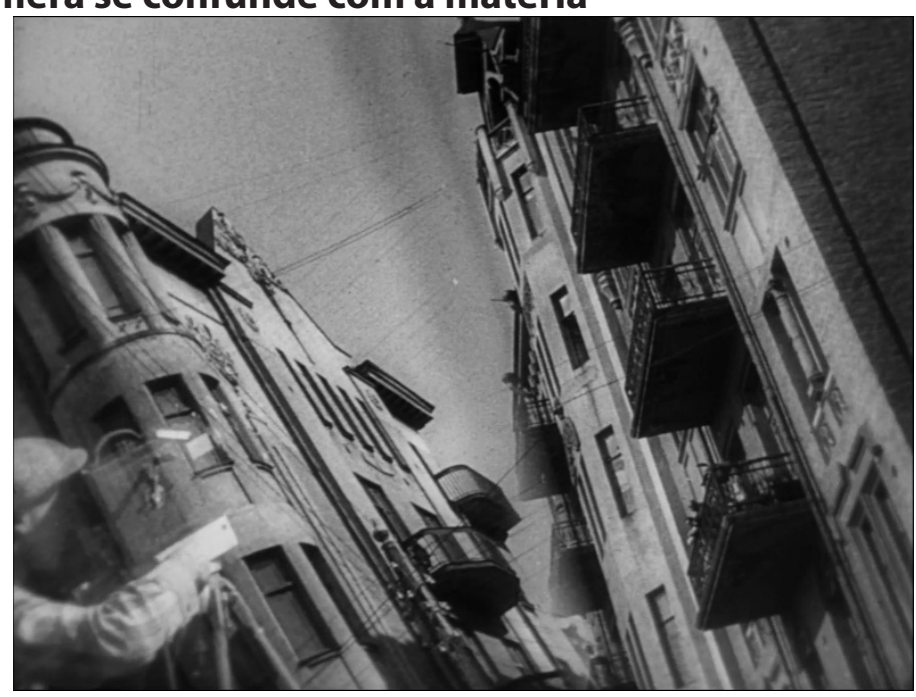

Fonte: O Homem com..., , Vertov, 1929

Quando analisa o trabalho de Vertov, Rancière (2012) destaca a utopia do cine-olho e o modo como ele seria capaz de instaurar um comunismo através da destituição do antropocentrismo do olho humano, sempre necessariamente sujeito ou assujeitado. Segundo Rancière, o que está no centro da questão de Vertov é a tensão entre a comunicação do movimento e a centralidade do olhar. O movimento do mundo transcende o próprio homem. O homem está inserido neste movimento de mundo, ao contrário do que se consolidou na visão antropocêntrica advinda do Renascimento. A câmera permitiria ao cineasta instalar-se no próprio movimento de mundo. Quando analisa O homem com a câmera, Rancière (2012) foca nesse ponto, qual seja, na primazia do movimento em Vertov, que é obtida através da autossupressão do cameraman. O cameraman está sempre lá, mas, ao mesmo tempo se autossuprime para inserir-se junto à câmera no fluxo dos movimentos do mundo.

Pode parecer contraditória a empolgação de Rancière por um cineasta que pautou sua produção a partir de um aparato técnico, já que, quando fala 
de estética e política, critica a perspectiva que faz a história da arte através da evolução dos seus aparatos técnicos. Num livro, critica Benjamin:

A tese benjaminiana, por sua vez, supõe outra coisa que me parece duvidosa: a dedução das propriedades estéticas e políticas de uma arte a partir de suas propriedades técnicas (Rancière, 2005, p. 45).

Noutro, celebra Vertov, que retira a potência de sua prática do aparato técnico cinematográfico e da sua supremacia frente ao olho humano (Rancière, 2012). Quando critica Benjamin, Rancière faz questão de se referir às influências que Benjamin sofreu de sua época: "ele acompanhou a fé nos poderes da eletricidade da máquina, do ferro, vidro ou concreto" (Rancière, 2005, p. 45). Ora, Vertov estava inserido no mesmo contexto e possivelmente tenha sido influenciado de modo ainda mais direto: "o 'psicológico' impede o homem de ser tão preciso quando o cronômetro, limita o seu anseio de se assemelhar à máquina" (Vertov, 1983b, p. 249). Então, por que Ranciére não faz a mesma acusação? Por que é generoso com Vertov e tão crítico quando se refere a Benjamin?

A questão é que em Vertov há uma expressividade artística no nível de uma estética primeira. Rancière insere Vertov e o cine-olho em um contexto evolutivo do regime estético das artes. Para ele, Benjamin quis estabelecer uma ruptura a partir da técnica, enquanto Vertov estava apenas utilizando a técnica para expandir o próprio regime estético (Rancière, 2012). Em última análise, o que Vertov faz em seu cinema é trabalhar a tensão fundamental entre os movimentos de mundo e a centralidade do olhar humano. Assim, traz um dilema fundamental, que para Rancière não é técnico, mas filosófico e político.

É necessário ter atenção quando se atribui a Vertov o paradigma da objetividade. O cineasta soviético rejeitava veementemente o cinema ficcional, sobretudo os dramas psicológicos, em nome de um cinema documental produzido como cine-olho (Vertov, 1983b). Dessa forma, não sem razão, é tido como um dos primeiros grandes documentaristas da história do cinema. A partir daí, decorre o equívoco de subsumir a potência de Vertov ao paradigma da imparcialidade e do objetivismo.

Fernão Ramos (2013) relata em detalhes o modo com que o trabalho de Vertov começou a repercutir na França, através do crítico de cinema George Sadoul. O trabalho de Vertov entrou na Europa ocidental através do conceito 
de "Cinema Verdade", traduzido do russo Kino-Pravda. Segundo Ramos, Sadoul traduziu a expressão no final dos anos 1940, atribuindo a ela a força de proposta estética do cinema de Vertov. Posteriormente, quando o conceito já havia ganhado força entre documentaristas franceses, o crítico reviu os originais e descobriu que a expressão Kino-Pravda era apenas o nome de um cinejornal que o diretor russo produzia para um jornal de informações cotidianas, intitulado Pravda. Logo, o que era apenas o título de um produto de notícias realizado por Vertov ganhou ares de uma proposta estética quando chegou à Europa ocidental.

Entre os conceitos de Cinema Verdade e de cine-olho existem diferenças que indicam séries distintas de problematizações dentro do universo do documentário. Em primeiro lugar, devemos observar que não é um caso fortuito Vertov ter talhado o conceito do seu cinema como kino-glaz, retomando-o em escritos por mais de uma década. A ideia de uma verdade e de um cinema que possa captar essa verdade como ela é, de modo imparcial, não é fundamental para o cinema de Vertov. Tanto que, para ele, existe o peso fundamental da montagem no processo cinematográfico, das sobreimpressões, das acelerações, das fragmentações, das câmeras lentas. Assim, denota-se em Vertov a ação do cineasta, em oposição a uma tradição de Cinema Verdade em que o cineasta deve neutralizar-se na busca de uma tomada da vida com ela é.

O novo documentário, particularmente em sua versão observativa (direto), é herdeiro de um cinema realista que mantém distância do construtivismo, seja em sua versão eisensteiniana, seja na recuperação construtivista da "vida de improviso" proposta por Vertov. A prática fílmica construtivista pensada por Vertov para fundar um novo cinema explicitamente não ficcional mantém pouca proximidade com elementos-chave do novo documentário, tanto no tipo de presença na circunstância da tomada, quanto nas demandas da montagem para a articulação narrativa (Ramos, 2013, p. 276).

Logo, consagrar a Vertov a designação de objetivista é temerário. Deleuze o faz, mas de acordo com um conceito preciso extraído de Bergson: objetivo é o olho da matéria. Não seria o olho de uma mosca que observa sem interferir (estilo cinema direto), tampouco o olho espiritual que se revela mais fundamental do que a matéria (estilo Jean Epstein). Este "olho da matéria" pode ser produzido através dos recursos cinematográficos que incluem o trabalho de 
câmera, mas também a montagem. Pela montagem é possível construir uma imagem-percepção que traz consigo uma visualidade objetiva, no sentido de que vai em direção à variação pura das coisas, em que o centro de referência não é constituído pelo olho humano. Dessa forma, a objetividade em Vertov não se opõe à montagem: "É preciso muito parti pris a Jean Mitry para denunciar em Vertov uma contradição que ele não ousaria, no entanto, censurar num pintor: a pseudocontradição entre a criatividade (da montagem) e a integridade (do real)" (Deleuze, 1983, p. 107).

Assim, após observar certa especificidade de Vertov, podemos compreender melhor o problema conceitual e político do seu cinema, o que nos levará a afirmar a necessidade de compreensão das imagens produzidas em fluxo nos protestos através de uma estética do cine-olho, de um "olho da matéria". O problema conceitual e político de Vertov não é apagar a individualidade em nome de uma suposta verdade, ou de uma suposta imagem direta do real. É, sobretudo, afirmar a inserção da individualidade neste grande fluxo que está além do próprio indivíduo. Esse grande fluxo pode receber vários nomes, como movimento ou energia. Trata-se, como notaram Rancière e Deleuze, de um projeto marxista no cinema. Contudo, é um projeto que apresenta uma potência que se mantém a despeito do ocaso das condições políticas em que floresceu. É o projeto estético que, segundo Rancière, traz a grande potência que existe na tensão entre o olho humano (individualista, sempre senhor ou assujeitado), e os movimentos de mundo: “Esse dilema não é técnico, mas filosófico e político. É o dilema da identidade entre o absoluto da vontade que interfere nas formas do mundo sensível, alterando-as, e a absoluta demissão da vontade em favor das energias de uma vida que nada quer" (Rancière, 2012, p. 50).

$\mathrm{Se}$, para Rancière, $\mathrm{O}$ homem com a câmera não pode ser visto como um filme que aposta tudo na demissão da individualidade em favor de um fluxo de movimento e energia, é porque ele traz consigo sempre a presença do homem, que manipula a câmera e que se oferece, que se demite em favor das energias vitais. Portanto, a estética do cine-olho de Vertov, sob esta perspectiva, possui uma dimensão política e filosófica que é consequência da sua prática radical. Evidentemente, o projeto de Vertov, quando se atualiza, adquire novas características que dizem respeito ao mundo novo no qual vem florescer, que agora não é mais o mundo da crença nas máquinas e na construção de uma sociedade comunista. O dilema entre a centralidade do olhar e os fluxos de mundo, porém, permanece e reconfigura-se, por meio de atualizações, em outras manifestações imagéticas, como aquelas produzidas através de câmeras 
em fluxo nos protestos havidos nos últimos anos, da África aos Estados Unidos, da Europa ao Brasil.

\section{Os protestos contemporâneos no "olho da matéria"}

Nas imagens de protestos, merecem destaque aquelas produzidas em fluxo, nas quais o portador da câmera participa do acontecimento. Seu objetivo não é apenas registrar o protesto, também é produzir o acontecimentoprotesto. O contexto contemporâneo permite-lhe produzir imagens e, às vezes instantaneamente, fazê-las proliferar em redes sociais e de compartilhamento.

No filme de Vertov, $O$ homem com a câmera, a presença do cameraman é fundamental. Nas imagens de protestos, preferimos referir a existência de portadores de câmeras. Denominamos portadores de câmera porque já estamos diante de alguém com características bastante diferentes em relação àqueles profissionais que operavam as máquinas cinematográficas nos anos 1920 . No contexto atual, os amadores que protestam registram as cenas com celulares e outros dispositivos móveis. Qualquer um pode se tornar um produtor de imagens e a ideia de autoria se reconfigura, como veremos adiante.

Vertov procurava o centro dos acontecimentos com a sua câmera, mas tinha que lidar com um equipamento pesado e uma equipe mínima de captação. Ele buscava inserir sua câmera, sempre acompanhada pelo operador, no fluxo dos acontecimentos, como nos trens e nos carros em movimento (Figura 5). As imagens de protesto não possuem essa necessidade básica de uma equipe. Pelo contrário, qualquer pessoa de dentro do protesto torna-se um produtor potencial de imagens. De certa forma, há uma inversão que radicaliza a lógica de Vertov: não é o homem com a sua câmera que se põe no fluxo; são os manifestantes ou repórteres-manifestantes em fluxo que se valem de suas câmeras. Na imagem abaixo, por exemplo, o repórter-manifestante tenta desesperadamente direcionar a câmera para o espaço não permitido, o buraco negro e hostil às câmeras do interior do carro da polícia em que estava detido um outro repórter-manifestante (Figura 6). 
Figuras 5 e 6: É preciso pôr a câmera em fluxo e cobrir todos os espaços

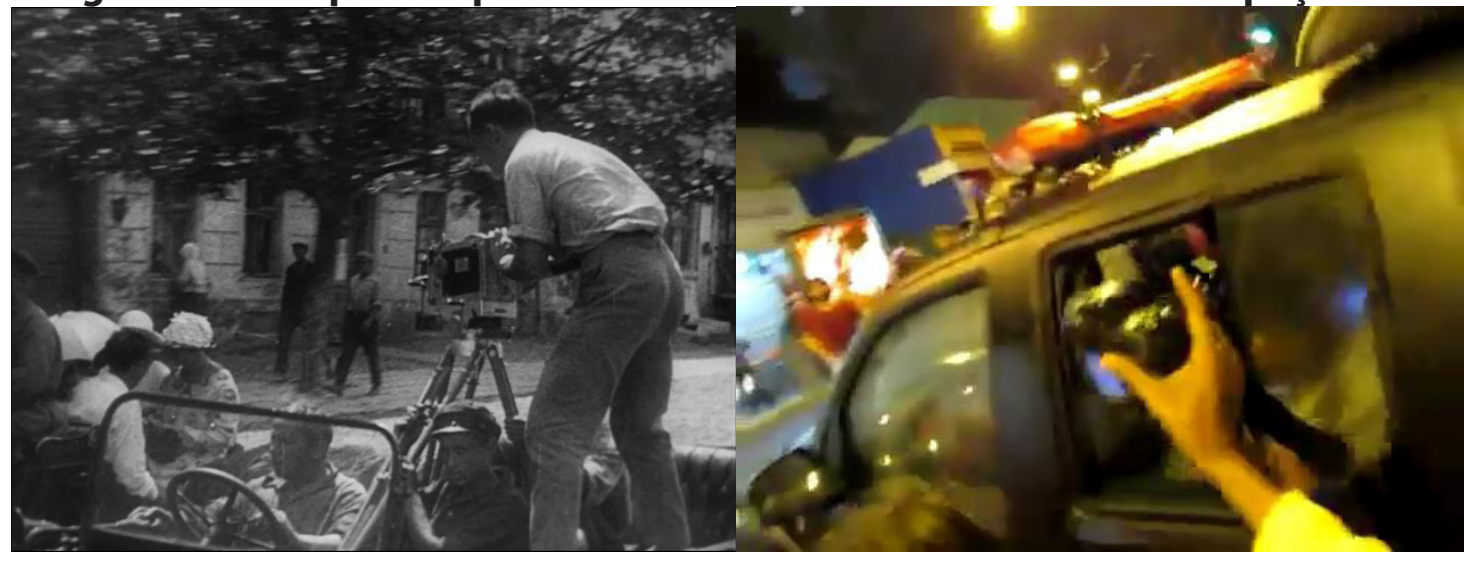

Fontes: O Homem com..., Vertov, 1929 e Prisão do Carioca..., sem autoria, 2013.

Paralelamente, se os manifestantes portadores de câmera tornamse produtores de imagens, também surgem coletivos de produção que se confundem com manifestantes. É o caso, por exemplo, da rede mídia NINJA, formada no Brasil em 2011, cuja sigla significa "Narrativas Independentes, Jornalismo e Ação". Esse jornalismo se caracteriza por tomar parte na multidão e não permanecer restrito ao paradigma do registro dos fatos:

Pensando na mídia livre, podemos dizer que o sujeito qualquer, o midialivrista, diferente do jornalista corporativo, não está em protesto, ato, manifestação, apenas para fazer o registro (ou reportar) dentro de uma relação de trabalho. Ele é um corpo da multidão e a comunicação é uma das formas de mobilizar e organizar, expressar, essa multidão (Bentes, 2016, p. 7).

Evidentemente, esta postura é alvo de críticas do ponto de vista do jornalismo tradicional. Destacamos nesse sentido as palavras de Fernando Gabeira: "Mas existem certos princípios na informação de qualidade. Um é a importância de ouvir os dois lados. Outro é a humildade do repórter, que mesmo tendo uma posição sobre determinado tema não tenta conformar a realidade à sua tese" (Gabeira, 2013).

De todo modo, as imagens feitas em fluxo de protestos borram a fronteira entre o fato e a cobertura do fato e parecem indicar que Gabeira utiliza parâmetros avaliativos que já não dão mais conta do que se processa 
no mundo da comunicação, de um lado, porque os próprios manifestantes em fluxo produzem suas imagens e, de outro, porque grupos dedicados à produção de imagens confundem-se com manifestantes em fluxo.

As imagens em fluxo tendem a possuir as marcas corporais da presença em ato dos portadores de câmera. O olhar que organiza, seleciona e enquadra torna-se uma força não predominante nessas imagens. Nas imagens abaixo (Figura 7), do vídeo O maior protesto contra a passagem em Porto Alegre! (Coletivo Catarse, 2013), o espaço está desenhado como duas trincheiras: a dos policiais protegidos por seus escudos e a dos manifestantes agrupados que se dirigem aos policiais com palavras que não podemos conhecer, porque o áudio ambiente foi suprimido da imagem em proveito de uma trilha sonora. Entre os dois grupos, a imagem mostra que o espaço intermediário permanece vazio, o que indica tanto o fato de constituir-se numa zona de risco, quanto o fato de que não existem interlocutores entre os dois grupos que se enfrentam. É a partir daí que o portador da câmera começa o plano-sequência que vemos na imagem: ele sai do grupo dos policiais, atravessa a zona intermediária e ingressa no grupo de manifestantes. A imagem sente o caminhar, perde o foco, desenquadra, quase cai. A câmera se dirige na direção do grupo de manifestantes com convicção, mas sem possuir um objetivo claro do ponto de vista do objeto a ser gravado. O objetivo da câmera é estar em presença, é fazer o trânsito de um lado a outro. Assim, os corpos vão entrando e saindo do enquadramento, quase sempre em partes, cabeças, pernas, mãos que não seguem quaisquer regras de composição. A imagem não cessa de se movimentar e, no movimento, não procura as melhores composições, nem os instantes privilegiados do movimento, nem os objetos significativos. $O$ valor da imagem aqui é sobretudo o de estar junto, estar no fluxo do acontecimento. A câmera penetra tanto que colide com um manifestante. Vemos na tela o cotovelo do manifestante no momento do choque. Finalmente, é o choque corporal que faz a câmera moverse e desenquadrar-se.

Seria impreciso afirmar que não existe a presença de um olhar que organiza a imagem. Contudo, o que se evidencia nessas imagens é que o olhar nesses termos perde a primazia, ele não impera mais sobre a imagem, que pode aproximar-se assim de um estado bruto da matéria. É verdade que estar no olho da matéria, fazer uma pura imagem-percepção, é um objetivo em última instância inalcançável, porque por definição sempre existe algum elemento de intencionalidade, o ligar da câmera, o virar-se para um lado, para o outro. É algo que Rancière destaca quando fala de Vertov: ali existe uma disputa entre o querer e o nada querer. 
Figura 7: Plano-sequência, desenho do espaço e corpo em ato na imagem
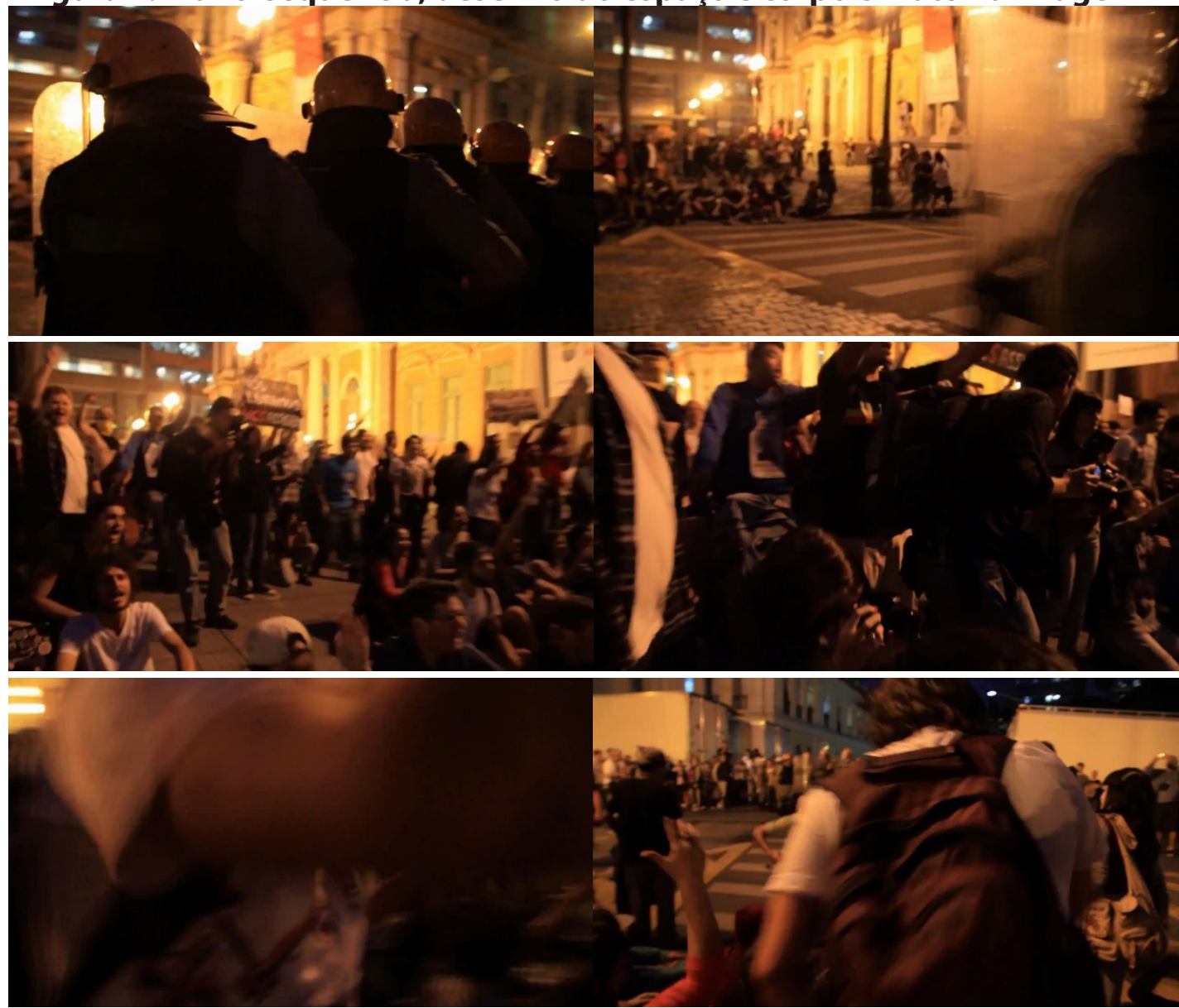

Fonte: O Maior protesto..., Coletivo Catarse, 2013.

Se manter a câmera presa ao corpo é uma estratégia que faz a imagem aproximar-se do olho da matéria em estado bruto, podemos ver que, às vezes, essa estratégia alterna-se com a precisão do olhar, que estabiliza a imagem para fazer sobressair um recorte específico da matéria. No vídeo Prisão do Repórter da Mídia Ninja (Sem autoria, 2013), o repórter jamais desliga a câmera enquanto está sendo abordado pelos policiais. As imagens são instáveis e às vezes beiram o abstrato. Todavia, em determinado momento, quando precisa e consegue, o repórter estabiliza o enquadramento sobre o rosto que ele deve identificar no meio da multidão: "Queria saber quem que é esse rapaz?", ouvimos (Figura 8). 
Figura 8: Em certos momentos é preciso enquadrar

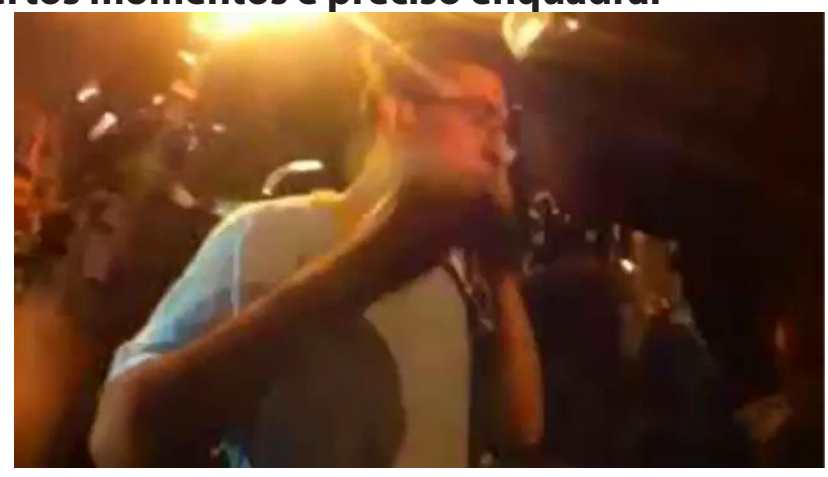

Fonte: Prisão do Repórter..., sem autoria, 2013

Posteriormente, no mesmo vídeo, a imagem vai perdendo os rastros de definição que possuía, fica cada vez mais abstrata e ininteligível, até desaparecer (Figura 9). É o momento em que o repórter é forçado pelos policiais a entrar na viatura em que as imagens não podem ser feitas. Nesse caso, vemos que a própria imagem vai se tornando um turbilhão sem forma, só podemos distinguir um foco de luz ao fundo e um rosto à direita do quadro. O repórter portador da câmera perde aos poucos o mínimo de autonomia que possuía para produzir a sua imagem, perde inclusive a autonomia para fazer variar a sua imagem entre um estado bruto, primazia do corpo em fluxo, e um estado organizado, primazia do olhar que seleciona. $O$ resultado é a imagem que definitivamente perde o centro e perde as formas até tornar-se impossível.

Figura 9: Imagem dissolve-se na abstração

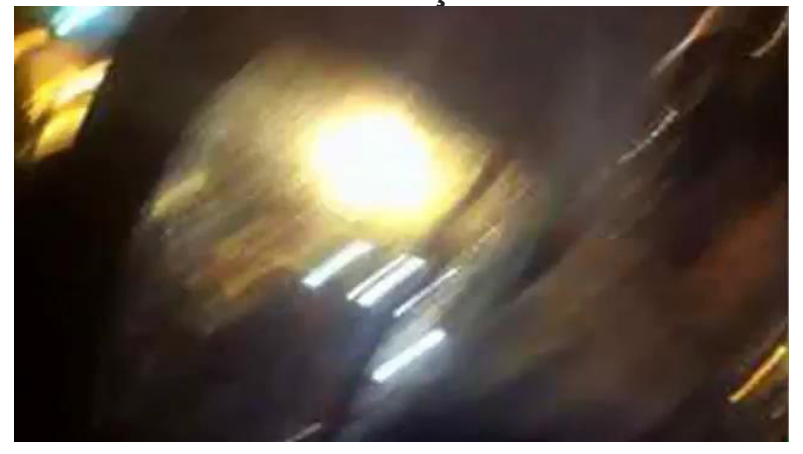

Fonte: Prisão do Repórter..., sem autoria, 2013

Outra característica das imagens produzidas em fluxo é que a identidade do realizador tende a perder importância, o que é um ponto central tanto na 
análise de Anita Leandro (2014), que afirma ser este um "cinema sem autor", quanto de Bentes (2016), que fala em parcialidades sem assinaturas. Nessas imagens, a singularidade que possui relevância em termos de autoria é a presença no fluxo do protesto. É como participante do fluxo do protesto - o olho da matéria - que o autor "assina" a imagem. As marcas dessa "assinatura" estão muitas vezes na baixa qualidade da captação, no desenquadramento da ação e nos movimentos bruscos da imagem que indicam a sua conexão com o corpo do manifestante. Sobre este aspecto, inclusive os coletivos de mídia tendem a fortalecer o projeto que os une em detrimento da autoria individualizada da imagem.

Com isso compreende-se porque a desindividualização é um dos principais focos de crítica por parte das análises políticas dos protestos. Assim como não há autoria das imagens no sentido tradicional do termo, também não há lideranças nos protestos. O fenômeno das máscaras indica uma problemática conexa, na medida em que elas servem não para esconder as individualidades dos manifestantes, mas para ressaltar as singularidades que conectam os participantes e os fazem partilhar de uma prática estético-política comum. Vemos, portanto, que há um trânsito entre questões estéticas e políticas e como o modo de produção de imagens está relacionado com esta partilha de sensíveis que se realizam com diferentes formas de expressão (culturais, sociais, políticas, tecnológicas).

Enfim, outra característica estética das imagens em fluxos de protestos é sua dinâmica de apropriação, montagem e narrativização. Há um território de disputa na apropriação dessas imagens em sua montagem e, principalmente, na construção de narrativas midiáticas. A consolidação de narrativas antihegemônicas é um desejo explícito manifestado na denominação da mídia NINJA, como vimos, e é um tema recorrente na montagem feita a partir de imagens de protestos em fluxo, inclusive com contraposição de imagens veiculadas pela mídia tradicional. Nesse sentido, podemos tomar como exemplo o vídeo de divulgação do FACÇÃO - Encontro Latino-Americano de Midiativismo (Figura 10), organizado e apoiado por pelo menos 36 coletivos de atuação midiática, e que aconteceu no Rio de Janeiro, de 22 a 24 de novembro de 2013.

Este vídeo do FACÇÃO realiza uma montagem a partir de diversos vídeos produzidos em protestos contrapostos a imagens da televisão tradicional, do cinema, de entrevistas de políticos, dentre outros. Ocorre, porém, que o vídeo produz uma reflexão específica a partir dessas fontes, uma narrativização própria a partir dessas mesmas imagens. No trecho abaixo, vemos frames em que imagens de protestos são montadas sucessivamente e articuladas através do texto escrito: "O VANDALISMO MEMÉTICO / QUEBRA A NARRATIVA / INVADE 
O IMAGINÁRIO / PROVOCA MOVIMENTO / SURGE UMA LEGIÃO MIDIATIVISTA / QUE EMPUNHA ARMAS SIMBÓLICAS".

Figura 10: Imagens são apropriadas, montadas e narrativizadas
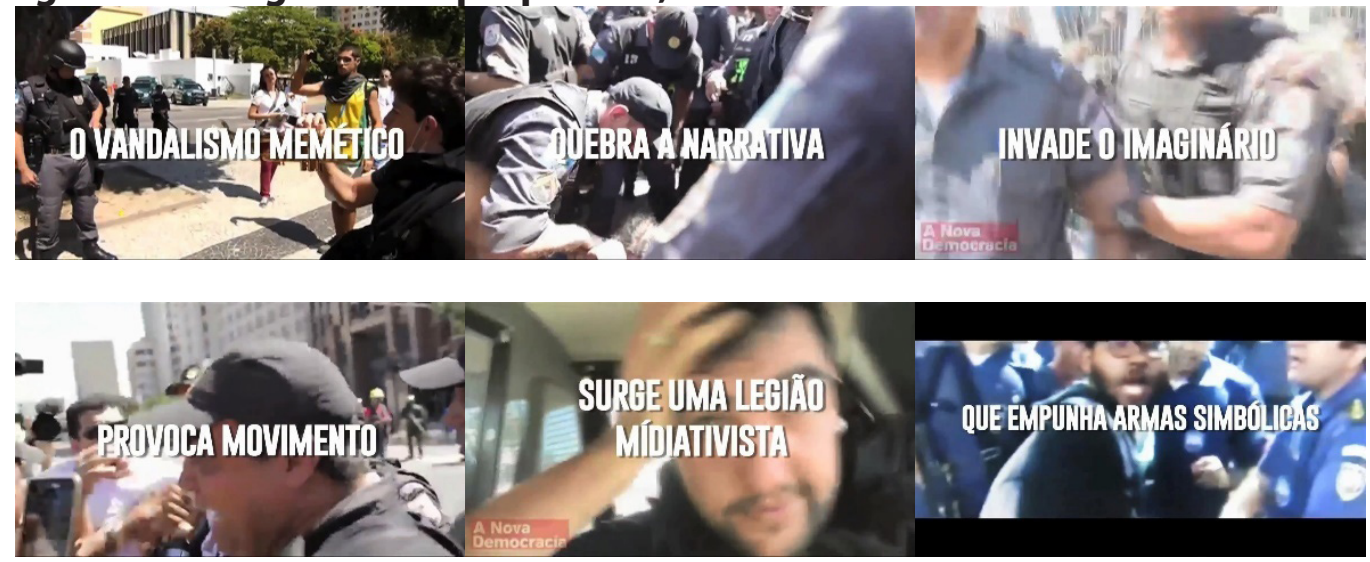

Fonte: Facção - Encontro Latino-Americano..., 2013

Existem aquelas montagens que aplicam efeitos sobre as imagens brutas, como time-lapse e sobreposições (Figura 11), o que é veementemente criticado por Anita Leandro. A autora alerta para o fato de os efeitos serem uma forma de reapropriação da imagem bruta por parte do espetáculo. Podemos citar também as apropriações que tornam essas imagens ilustrações em videoclipes, o que certamente também pode contribuir para esvaziar o "conteúdo político das imagens de risco":

As imagens estão sempre a flertar com o espetáculo, como aconteceu, por exemplo, com alguns filmes sobre as manifestações de junho de 2013 no Brasil, ao reproduzirem, de maneira automatizada, efeitos especiais de montagem sem relação com a situação filmada: o efeito acelerado (time-lapse), por exemplo, aplicado a planos longos de passeatas em vários vídeos postados na internet, em nada contribuiu para um estudo dos fatos. Ao contrário, a reprodução automatizada dos clichês midiáticos na montagem tende a esvaziar o conteúdo político das imagens de risco (Leandro, 2014, p. 129). 
- Figura 11: Sobreposição e time-lapse: efeitos que podem espetacularizar a imagem

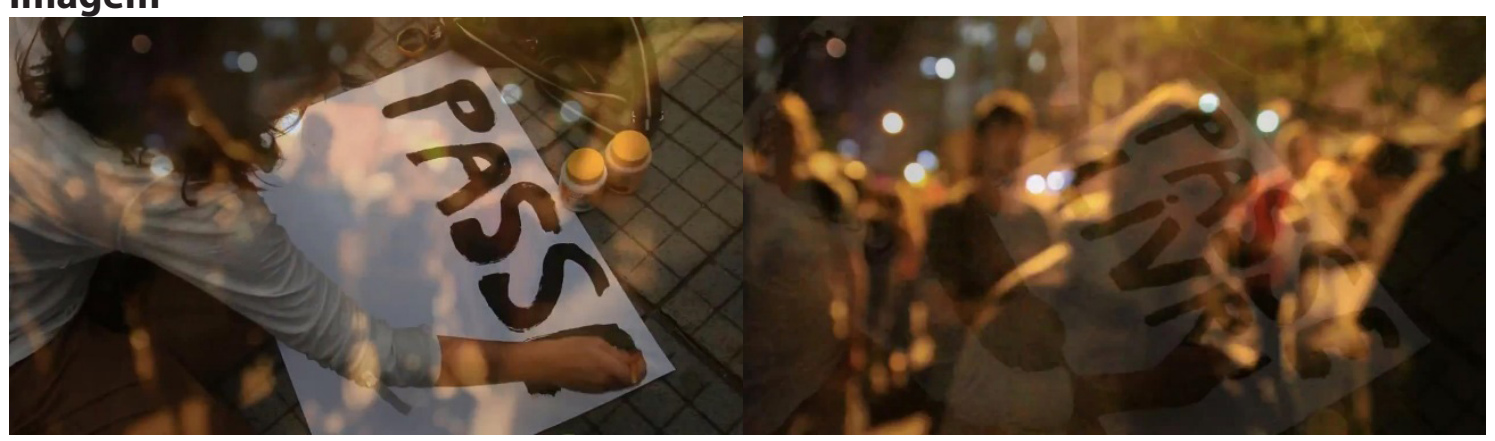

Fonte: O Maior protesto..., Coletivo Catarse, 2013

A liberdade do processo de montagem atualiza contemporaneamente e com outros vieses a estética do cine-olho vertoviana. Como vimos, Vertov faz uma utilização experimental da montagem sem a necessidade de permanecer submetido à integridade do real. É verdade que Vertov não narrativiza, ao contrário de muitas das apropriações que vemos acontecerem nas imagens de fluxos de protestos. É comum vermos pequenas histórias que se compõem a partir do material bruto. Em Prisão do repórter da mídia Ninja (Sem autoria, 2013), foi preciso adicionar imagens de outras câmeras para completar a pequena narrativa, para fazer com que a narrativa da prisão não terminasse com o repórter sendo forçado a desligar a sua câmera e a entrar na viatura de polícia, mas com a resistência dos manifestantes que primeiro tentam evitar a partida da viatura e, depois, se aglomeram em frente ao prédio reivindicando a liberação do repórter. Em O maior protesto contra a passagem em Porto Alegre! (Coletivo Catarse, 2013) são utilizados letreiros que fazem as demarcações narrativas na imagem.

Também acontece de os vídeos recorrerem à palavra para atribuir sentido às imagens. Em $R J$-Cenas exclusivas da corajosa resistência das massas à violência da PM em ato no Leblon (ANG produções e jornal A Nova Democracia, 2013), após uma sequência de imagens de confrontos, o vídeo apresenta uma entrevista realizada após o confronto, em local de atendimento médico, que serve para atribuir sentido ao conjunto de imagens em estado quase bruto. Na entrevista, o manifestante afirma: "Brother, mirar na minha garganta foi o cúmulo. Sacou? Mirar na minha garganta? Eu vou voltar! Eu vou voltar com mais raiva". A imagem seguinte, que encerra o vídeo, tem a mesma função. O manifestante segura o cartaz no qual se lê: "A barricada fecha a rua para abrir novos caminhos". 


\section{Considerações Finais}

Como afirma Rancière, a estética está na base da política. A estética é responsável por instaurar novas visibilidades e dizibilidades, ao passo que a política gere aquilo que pode ser visto e dito. De modo que, quando adentramos nas práticas de apropriação das imagens de protestos, entramos mais diretamente no nível da política. O medo e o protagonismo das câmeras nos protestos nos revelam como é ameaçadora a possibilidade de imagem. Neste artigo, oferecemos elementos para uma compreensão dessas imagens: uma base teórica (estética e política em Ranciére), uma ancoragem na história do cinema (cine-olho em Vertov), uma análise de elementos estéticos (predominância do corpo, mas alternada com estabilidade do olhar, momentos de abstração e perda de forma, apropriações que montam e narrativizam as imagens). Temos consciência, contudo, que é preciso compreender a dimensão política que essas imagens vêm desestabilizar e com as quais elas se agenciam. Podemos entrever alguns elementos nesse sentido: a crítica à autoria e à identidade, a emergência de novas formas de organização que se refletem tanto na produção de imagens quanto no modo de organização coletiva dos protestos, a perda dos padrões de qualidade e confiabilidade da imagem, tão necessários no jornalismo tradicional, a não externalidade do produtor de imagens com relação aos acontecimentos, e, consequentemente, a crítica à institucionalização da comunicação de modo geral. São elementos, estes, que apenas podemos indicar, mas que correspondem a impactos políticos em parte concomitantes e em parte posteriores à emergência dessas imagens. Deleuze (1985) disse que com relação às imagens-percepção seria preciso conhecer os agenciamentos nos quais elas tomam parte, os agenciamentos coletivos de enunciação que elas vêm fomentar. Parece-nos que este é um desafio ainda necessário no que tange às imagens de protestos, qual seja, de conhecer as ressonâncias políticas que essas imagens puderam e podem agenciar, e inclusive se somos capazes de suportar o desejo radical de imagem que elas demonstram ao aproximar a câmera do olho da matéria.

\section{REFERÊNCIAS}

A PARTIR de agora. Realização: PRONZATO, Carlos. 2014.

BENJAMIN, Walter. A obra de arte na era da sua reprodutibilidade técnica. Magia e técnica, arte e política - ensaios sobre literatura e história da cultura. São Paulo: Brasiliense, 1987. 
BENTES, Ivana. Mídia-multidão: estéticas da comunicação e biopolíticas. Rio de Janeiro: Mauad X, 2016.

BREAKING the spell. Realizado por: LEWIS, Tim; REAM, Tim; ROCK, Sir Chuck A. 1999.

COM VANDALISMO. Realização: Coletivo Nigéria, 2013.

DELEUZE, Gilles. A imagem-movimento. São Paulo: Brasiliense, 1985.

FACÇÃO - Encontro Latino-Americano de Midiativismo. Realizado por: Facção. 2013. Disponível em: <http://www.faccao.org/>. Acesso: 25 nov. 2013.

GABEIRA, Fernando. Mídia Ninja e o futuro desfocado. Estadão, São Paulo, 16 ago. 2013. Disponível em: <http://www.estadao.com.br/noticias/impresso,midianinja-e-o-futuro-desfocado, 1064592,0.htm>. Acesso em: 15 dez. 2013.

LAPA 5a DP 27/08/2013 Black Bloc Rio de Janeiro. Sem autoria. Publicado por: Prezz Libre, em 27 ago. 2013. Disponível em: <https://www.youtube.com/ watch?v=eBam-Hx1Zuk>. Acesso em: 15 mar. 2016.

LEANDRO, Anita. Sem imagens: memória histórica e estética de urgência no cinema sem autor. Estudos da língua(gem), Vitória da Conquista, v. 12, n. 1, p. 121-134, jun. 2014. Disponível em: <http://www.estudosdalinguagem.org/index.php/ estudosdalinguagem/article/view/415/374 >. Acesso em: 15 fev. 2016.

O HOMEM com a câmera. Realização: VERTOV, Dziga. 1929.

O maior protesto contra a passagem em Porto Alegre! Realização: Coletivo Catarse. Publicado por: Coletivo Catarse, em 28 mar. 2013. Disponível em: <https://www. youtube.com/watch?v=PoLuEXcurB >. Acesso: 15 mar. 2016.

PRISÃO do Carioca - Mídia Ninja. Sem autoria. Publicado por: Felipe Buarque, em 22 jul. 2013. Disponível em: <https://www.youtube.com/watch?v=SIINOilQ680 >. Acesso em: 15 mar. 2016.

PRISÃO do Repórter da Mídia Ninja. Sem autoria. Publicado por: PosTV, em 31 jul. 2013. Disponível em: <https://www.youtube.com/watch?v=aDO6tr6kgAk>. Acesso em: 15 mar. 2016.

RAMOS, Fernão. Mas afinal... O que é mesmo documentário? São Paulo: SENAC São Paulo, 2013.

RANCIÈRE, Jacques. A partilha do sensível - arte e política. São Paulo: EXO Experimental (org.); Ed. 34, 2005.

RANCIÈRE, Jacques. As distâncias do cinema. Rio de Janeiro: Contraponto, 2012.

REPÓRTER da TV Folha e manifestante são agredidos pela polícia. Realização: TV Folha, 2011. Disponível em: <http://www.youtube.com/ 
watch?v=fCfxshW2OME $>$. Acesso em: 15 mai. 2013.

RJ - CENAS exclusivas da corajosa resistência das massas à violência da PM em ato no Leblon. Realização: ANG produções e Jornal A Nova Democracia. Publicado por: Jornal A Nova Democracia, em 18 de jul. 2013. Disponível em: <https:// www.youtube.com/watch?v=eWew1wliLul>. Acesso em: 15 mar. 2016.

30 FRAMES a second: the WTO in Seatle. Realização: THOMPSON, Rustin, 2000.

THIS IS what democracy looks like. Realizado por: FRIEDBERG, Jill; ROWLEY, Rick. 2000.

VERTOV, Dziga. Resolução do conselho de três (10/4/23). In: XAVIER, Ismail (Org.). A experiência do cinema - antologia. Rio de Janeiro: Edições Graal / Embrafilme, 1983a.

VERTOV, Dziga. NÓS - Variação do manifesto. In: XAVIER, Ismail (Org.). A experiência do cinema - antologia. Rio de Janeiro: Edições Graal / Embrafilme, 1983b.

Recebido em: 30/6/2016

Aceito em: 4/7/2016

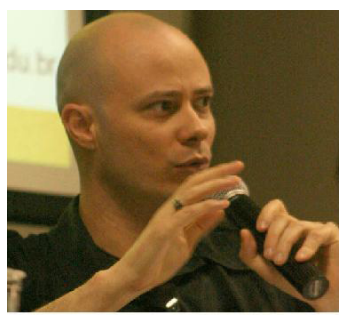

Endereço dos autores:

Alexandre Rocha da Silva <arsrocha@gmail.com>

Programa de Pós-Graduação em Comunicação e Informação da Faculdade de Biblioteconomia e Comunicação da Universidade Federal do Rio Grande do Sul (UFRGS)

Rua Ramiro Barcelos, 2705 - Prédio 22201

Bairro Santana - Campus Saúde

90035-007 - Porto Alegre - RS - Brasil

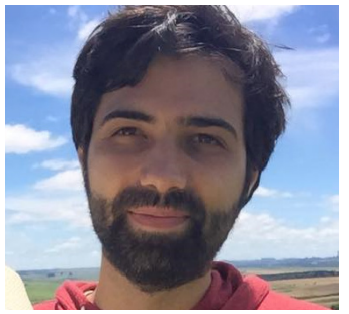

Bruno Bueno Pinto Leites < bleites2003@hotmail.com>

Universidade Federal de Pelotas (UFPel) - Curso de Cinema

Rua Alberto Rosa, 62 - Salas 301/311

96010 - 770 - Pelotas - RS - Brasil 